\title{
Development of an assay for antibodies to Saccharomyces cerevisiae: Easy, cheap and specific for Crohn's disease
}

\author{
Charles N Bernstein $\mathrm{MD}^{1,2}$, Ken Orr PhD ${ }^{1,3}$, James F Blanchard MD PhD ${ }^{2,4}$, \\ Michael Sargent ${ }^{1}$, Donna Workman ${ }^{3}$
}

CN Bernstein, K Orr, JF Blanchard, M Sargent, D Workman. Development of an assay for antibodies to Saccharomyces cerevisiae: Easy, cheap and specific for Crohn's disease. Can J Gastroenterol 2001;15(8):499-504.

OBJECTIVE: To develop a serological test to measure antibodies to Saccharomyces cerevisiae in patients with inflammatory bowel disease.

METHODS: An ELISA to the mannan of $S$ cerevisiae that is commercially available was developed. Sera were tested from randomly chosen sera specimens kept frozen at the University of Manitoba Inflammatory Bowel Disease Clinical and Research Centre, Winnipeg, Manitoba. Clinical diagnoses were kept blinded until the assay results were finalized. One hundred thirty-six sera were tested, including 51 with Crohn's disease, 32 with ulcerative colitis, one with indeterminate colitis and 16 other control subjects. Thirty-six samples were duplicates from patients already studied but were either run on separate days or drawn on different days.

RESULTS: Using a cutoff of 15 binding units as a positive result, Crohn's disease was found to have a sensitivity of 53\% but a specificity of $100 \%$ compared with ulcerative colitis. Compared with all other diagnoses (including ulcerative colitis), Crohn's disease had a sensitivity of $53 \%$ and a specificity of $96 \%$. For patients with Crohn's disease only, those who were anti-S cerevisiae antibody (ASCA) positive $(n=27)$ were significantly more likely to have proximal gastrointestinal disease and significantly less likely to have colonic or inflammatory type disease than those who were ASCA negative $(n=24)$. The direct cost of this assay was $\$ 6.00$ per positive test, and the total charge was set at $\$ 38.15$.

CONCLUSIONS: A reasonably inexpensive, easy and reproducible assay to assess for antibodies to $S$ cerevisiae has been developed. Using a cutoff for positivity of 15 binding units, this test had a specificity of $100 \%$ for ruling out Crohn's disease and a lower $(60 \%)$ sensitivity compared with ulcerative colitis. This test could identify a specific phenotype of patients with Crohn's disease as being more likely to have small bowel Crohn's disease and less likely to have colonic (isolated) or inflammatory disease, as opposed to fibrostenotic disease or penetrating disease. The test proved reliable when assaying samples drawn or assayed on different days.

Key Words: Crohn's disease; Inflammatory bowel disease; Saccharomyces cerevisiae

Pour le résumé, voir page suivante

University of Manitoba, Departments of ${ }^{1}$ Internal Medicine and ${ }^{4}$ Community Health Sciences; ${ }^{2}$ Inflammatory Bowel Disease Clinical and Research Centre; ${ }^{3}$ St Boniface General Hospital Immunology Laboratory, Winnipeg, Manitoba

Correspondence: Dr Charles N Bernstein, 804F-715 McDermot Avenue, John Buhler Research Centre, Winnipeg, Manitoba R3E 3P4.

Telephone 204-789-3369, fax 204-789-3987, e-mail cbernst@cc.umanitoba.ca

Received for publication March 13, 2001. Accepted April 26, 2001 


\section{Mise au point d'un dosage des anticorps anti-Saccharomyces cerevisiae : facile, économique et spécifique à la maladie de Crohn}

OBJECTIF : Mettre au point un test sérologique permettant de mesurer les anticorps dirigés contre Saccharomyces cerevisiae chez les patients souffrant d'une maladie inflammatoire de l'intestin.

MÉTHODE : Un test selon la technique ELISA, sensible à la mannane de S. cerevisiae, offert commercialement, a été mis au point. Des sérums provenant de prélèvements choisis au hasard et gardés congelés à l'Inflammatory Bowel Disease Clinical and Research Centre de l'Université du Manitoba, à Winnipeg, au Manitoba, ont été soumis au test; les diagnostics ont été gardés secrets jusqu'à ce que les résultats finaux des dosages soient connus. Cent trente-six sérums ont été analysés : 51 provenaient de patients atteints de la maladie de Crohn (MC); 32, d'une rectocolite hémorragique $(\mathrm{RH})$; 1 , d'une colite d'origine indéterminée; 16, de sujets témoins. Trente-six prélèvements de patients déjà à l'étude ont été analysés deux fois, c'est-à-dire qu'ils ont été examinés ou obtenus à des jours différents.
RÉSULTATS : À partir d'un seuil de 15 unités de liaison donnant des résultats positifs, on a constaté que le test avait une sensibilité de $53 \%$ mais une spécificité de $100 \%$ à l'égard de la MC comparativement à la RH. Quant à l'ensemble des autres maladies, RH comprise, la sensibilité et la spécificité étaient de $53 \%$ et de $96 \%$ respectivement à l'égard de la MC. Parmi les patients atteints de la MC seulement, ceux qui se sont montrés positifs à l'égard des anticorps anti-S. cerevisiae $(\mathrm{n}=27)$ étaient beaucoup plus susceptibles de souffrir d'une maladie gastro-intestinale proximale et beaucoup moins susceptibles d'être atteints d'une maladie du côlon ou d'une maladie inflammatoire que ceux qui ont obtenu des résultats négatifs $(n=24)$. Le coût direct du dosage a été de 6,00 \$ par test positif et les frais totaux ont été établis à 38,15 \$.

CONCLUSION : Un test relativement peu cher, facile d'utilisation et reproductible de dosage des anticorps anti-S. cerevisiae a été mis au point. À partir d'un seuil de positivité de 15 unités de liaison, le test a montré une spécificité de $100 \%$ pour exclure la MC et une sensibilité plus faible de $60 \%$ comparativement à la RH. Le test pourrait permettre de dépister un certain phénotype de patients atteints de la MC, plus susceptibles de souffrir de la MC de l'intestin grêle et moins susceptibles d'avoir une maladie isolée du côlon ou une maladie inflammatoire par opposition à une maladie fibrosténosée ou perforante. Le test s'est avéré fiable pour le dosage des prélèvements effectués ou analysés à des jours différents.
T here has been a burgeoning interest over the past decade in finding a simple serological test that can aid in the diagnosis of Crohn's disease and ulcerative colitis. There has been much enthusiasm for the antineutrophil cytoplasmic antibody with perinuclear staining ( $\mathrm{p}$-ANCA) test in diagnosing ulcerative colitis (1-4). Studies in ulcerative colitis have been replicated by several groups, and typically report a sensitivity of approximately $70 \%$ and a specificity of approximately $85 \%$ for diagnosing ulcerative colitis. The antigen is located on the inner side of the nuclear periphery and is DNAse sensitive. Recently, a DNAse step has been added by some centres to increase the specificity of the test for diagnosing ulcerative colitis (5). Indeterminate colitis represents approximately $5 \%$ of chronic colitis cases (6). This is one clinical scenario in which the availability of a simple serological test to diagnose ulcerative colitis or Crohn's colitis would be welcomed. However, a report that $50 \%$ of patients with Crohn's colitis were p-ANCA positive suggests a limited value for $\mathrm{p}$-ANCA testing alone to distinguish these entities (7). This finding was corroborated by others (8).

In 1988, there was a report of the use of antibody to Saccharomyces cerevisiae to identify Crohn's disease (9). Anti-S cerevisiae antibodies (ASCA) are directed against cell wall oligomannosidic epitopes. An assay was developed using the crude mannan from $S$ cerevisiae uvarum $I$ as the antigen (10). Data have shown that this antibody is only approximately $50 \%$ to $60 \%$ sensitive but approximately $90 \%$ specific for Crohn's disease $(8,10,11)$. The high specificity of an antibody test would be of value in cases in which it is otherwise difficult to distinguish Crohn's disease from ulcerative colitis. In North America, ASCA testing is available through Prometheus Laboratories, San Diego, California.
For Canadian centres, the use of ASCA is costly. The cost is at least US\$140, which at the current currency exchange rate is approximately CDN $\$ 210$ per negative sample and US\$445 (approximately CDN\$670) for a positive sample. These high costs reflect the fact that when ASCA is requested, a panel of antibodies are tested, including $\mathrm{p}$-ANCA.

We report the development of a simple, inexpensive assay for ASCA that is highly specific for Crohn's disease. We found a mannan that is commercially available from Sigma Diagnostics (St Louis, USA) and established an ASCA ELISA.

\section{METHODS}

One hundred thirty-six sera were randomly selected from a serum bank established for studies of inflammation and inflammatory markers from the University of Manitoba Inflammatory Bowel Disease Clinical and Research Centre, Winnipeg, Manitoba. Patient data included diagnosis, date of sera collection and, for Crohn's disease patients, site and nature of disease according to the Vienna Classification (12). ASCA was performed on these samples blinded to the diagnoses.

The ASCA assay was developed at the St Boniface Immunology Laboratory, Winnipeg, Manitoba. This laboratory runs the immunological antibody tests for the province of Manitoba, including tests for antibodies to extractable nuclear antigens (in the diagnosis of connective tissue diseases), endomysium and tissue transglutaminase (in the diagnosis of celiac disease), and ANCA.

Preparation of mannan: Mannan from $S$ cerevisiae $(0.02 \mathrm{~g})$ (Sigma Diagnostics, USA) was added to $100 \mathrm{~mL}$ of Coon's buffer and dissolved at room temperature. This solution was aliquoted in $1 \mathrm{~mL}(200 \mu \mathrm{g} / \mathrm{mL})$ quantities and frozen at 
$-70^{\circ} \mathrm{C}$. For the coating process, an aliquot was diluted to $20 \mu \mathrm{g} / \mathrm{mL}$ in Coon's buffer, and $0.15 \mathrm{M}$ sodium chloride, $0.02 \mathrm{M}$ potassium phosphate and $0.05 \mathrm{M}$ sodium phosphate (pH 7.1) were used.

Coating of plates: Immunolon 2HB'U' bottom, 96-well plates of irradiated protein-binding polystyrene were purchased from Dynex Technologies Inc (Chantilly, USA). Eighty microlitres of $20 \mu \mathrm{g} / \mathrm{mL}$ mannan was added to the first 48 wells of a 96-well plate. Eighty microlitres of Coon's buffer was added to the last 48 wells, providing a serum blank. The plate was incubated overnight at $4^{\circ} \mathrm{C}$ in a covered container.

ELISA procedure: All sera were tested in duplicate. The coating buffer was aspirated, and $100 \mu \mathrm{L}$ of $1 \%$ bovine serum albumin (BSA) in Coon's buffer with azide was dispensed into the wells and incubated at room temperature for $1 \mathrm{~h}$. All sera were diluted $1 / 1000$ with $1 \%$ BSA in Coon's buffer (containing 0.05\% Tween 20 and 0.025\% sodium azide) before use. The BSA was aspirated and the wells were washed three times with Coon's buffer (containing Tween 20). Fifty microlitres of diluted calibrators, patient sera or control sera was added to both sides of the plate and incubated for $1 \mathrm{~h}$ at room temperature. The plate was washed three times in Coon's buffer (containing Tween 20). Fifty microlitres of goat antihuman immunoglobulin (Ig) (IgG, IgA and IgM) alkaline phosphatase (Biomedicals Inc, USA) conjugate (diluted $1 / 4000$ in Coon's buffer above - determined to give optimal results with the lowest background) was added to the wells and incubated for $1 \mathrm{~h}$ at room temperature. The plate was then washed three times.

Fifty microlitres of a $1 \mathrm{mg} / \mathrm{mL}$ solution of freshly prepared P-nitrophenylphosphate (Sigma Diagnostics, USA) in $10 \%$ diethanolamine buffer was added and incubated at $37^{\circ} \mathrm{C}$ for $30 \mathrm{~min}$, after which $50 \mu \mathrm{L}$ of $2 \mathrm{~N}$ sodium hydroxide was added to stop the reaction. The wells were read at 405/590 nm on a spectrophotometer (PLAB, Biochem Immunosystems, Canada).

Calibration curve: The serum of a patient with a high absorbance value was designated as having 100 binding units $/ \mathrm{mL}$. This sample was then serially diluted and used to produce a calibration curve. Unknown samples were then compared with this curve and assigned units based on where on the absorbance curve they appeared, or the absorbances of unknown samples were compared with a group of normal samples in which means and standard deviations had been calculated (see below).

Control sera: Three patients were selected with binding units in the high, medium and low ranges of the curve. These were included in each run to check for precision. A number of normal sera were also run in each assay to determine the negative cutoff and standard deviations.

Calculations: The means, standard deviations and coefficients of variation of the absorbances were calculated for all the tests. The coefficients of variation had to be less than $10 \%$ to be acceptable. For the group of normal samples, the mean +1 SD and mean +2 SD were calculated. All samples above $2 \mathrm{SD}$ were rejected. The mean was recalculated with 1 SD, 2 SD and 3 SD. These values were used to determine the normal range and patient status. It should be noted that these absorbance values are comparable with the binding units that were also calculated. Receiver operating characteristic (ROC) curves were constructed by plotting the sensitivity of the test (y axis) against one specificity ( $\mathrm{x}$ axis) for each cutoff value for the test. In this way, the tradeoffs between sensitivity and specificity can be explored. The area under the ROC curve describes the overall accuracy of the test in predicting the true state, with higher values denoting tests with higher predictive value.

Normal range: The normal range was calculated as described above. The categories for reporting purposes are as follows:

Negative: less than mean +2 SD of a group of normal samples (less than 15 binding units $/ \mathrm{mL}$ )

Borderline: less than mean +3 SD of a group of normal samples (15 to 20 binding units $/ \mathrm{mL}$ )

Positive: greater than mean $+3 \mathrm{SD}$ of a group of normal samples (more than 20 binding units $/ \mathrm{mL}$ )

The authors have decided that reporting of positive versus negative status rather than binding units provides all the relevant information to the clinician.

Assay costs: The material cost to perform ASCA testing is approximately $\$ 1.00$ per patient. The technical cost is approximately $\$ 5.00$ per patient. The total direct cost is in the range of approximately $\$ 6.00$ per patient. This does not include the indirect costs of building maintenance, such as ELISA analyzer, space, electricity, water, etc. The laboratory cost for this newly developed ASCA assay is $\$ 38.15$ per sample. This accounts for direct, indirect and reporting costs. The laboratory cost for the ANCA assay is $\$ 35$ per sample, which accounts for all costs.

Statistical analysis: Fisher's exact test with two-tailed $\mathrm{P}$ values was used to compare proportions, and Student's $t$ test was used to compare the mean age at diagnosis in Crohn's disease patients.

\section{RESULTS}

Of the 136 samples run, 51 were positive for Crohn's disease, 32 were positive for ulcerative colitis, 14 were normal, one was positive for indeterminate colitis, one was positive for lymphocytic colitis and one was positive for celiac disease. Thirty-six samples were repeat samples from patients already tested, either from sera drawn on a different day $(n=15)$ or from sera drawn on the same day but assayed on different days $(n=21)$. Tables 1 to 3 present the data using a cutoff for positivity of 10 binding units (Table 1), 15 binding units (Table 2) and 20 binding units (Table 3) for Crohn's disease compared with ulcerative colitis, and for Crohn's disease compared with all other diagnoses (including normal results, lymphocytic colitis and celiac disease). Fifteen patients (eight with Crohn's disease, six with ulcer- 
TABLE 1

Utility of anti-Saccharomyces cerevisiae antibody testing using a cutoff of 10 binding units, comparing Crohn's disease (CD) sera with those of ulcerative colitis (UC) and other diagnoses

\begin{tabular}{lcc}
\hline & $\begin{array}{c}\text { CD }(\mathbf{n}=\mathbf{5 1}) \\
\text { versus } \mathbf{~ U C ~}(\mathbf{n}=\mathbf{3 2})\end{array}$ & $\begin{array}{c}\text { CD }(\mathbf{n}=\mathbf{5 1}) \\
\text { versus other* }(\mathbf{n}=\mathbf{4 8})\end{array}$ \\
\hline Sensitivity & 56.9 & 56.9 \\
Specificity & 100 & 87.5 \\
Positive predictive value & 100 & 82.9 \\
Negative predictive value & 59.3 & 65.6 \\
Correctly classified & 73.5 & 71.7 \\
\hline
\end{tabular}

*Includes 32 UC, one CD, one lymphocytic colitis and 14 normal controls. One patient with indeterminate colitis was positive and left out of the analysis. Fifteen patients (eight $C D$, six UC, one indeterminate) had samples from different days run; $100 \%$ gave concordant results. Twentyone patients (13 CD, eight UC) had samples from the same day run on different days; 18 (85.7\%) gave concordant results and three (14.3\%) gave discordant results

TABLE 2

Utility of anti-Saccharomyces cerevisiae antibody testing, using a cutoff of 15 binding units, comparing Crohn's disease (CD) sera with those of ulcerative colitis (UC) and other diagnoses

\begin{tabular}{lcc}
\hline & $\begin{array}{c}\text { CD }(\mathbf{n = 5 1}) \\
\text { versus UC }(\mathbf{n = 3 2})\end{array}$ & $\begin{array}{c}\text { CD }(\mathbf{n = 5 1}) \\
\text { versus other* }(\mathbf{n = 4 8})\end{array}$ \\
\hline Sensitivity & 52.9 & 52.9 \\
Specificity & 100 & 95.8 \\
Positive predictive value & 100 & 93.1 \\
Negative predictive value & 57.1 & 65.7 \\
Correctly classified & 71.1 & 73.7 \\
*Includes 32 UC, one CD, one lymphocytic colitis and 14 normal con- \\
trols. One patient with indeterminate colitis was positive and left out of \\
the analysis. Fifteen patients (eight CD, six UC, one indeterminate) had \\
samples from different days run; 14 (95.2\%) gave concordant results and \\
one (4.8\%) gave discordant results. Twenty-one patients (13 CD, eight \\
UC) had samples from the same day run on different days; 20 (95.2\%) \\
gave concordant results and one (4.8\%) gave discordant results
\end{tabular}

ative colitis and one indeterminate) had samples run from different days; 14 (95.2\%) gave concordant results and one gave discordant results (4.8\%) using 15 binding units as the cutoff. Twenty-one patients (13 with Crohn's disease, and eight with ulcerative colitis) had samples from the same day run on different days; 20 (95.2\%) gave concordant results and one $(4.8 \%)$ gave discordant results.

Upon discovery of a positive result in a patient with celiac disease, 30 samples from known antiendomysial antibody-positive patients with celiac disease were run; three of 30 samples were positive by ASCA assay.

ROC curves were created for sensitivity and specificity of distinguishing Crohn's disease from ulcerative colitis (Figure 1) and Crohn's disease from all other diagnoses (Figure 2). This analysis showed that the test performed well for distinguishing Crohn's disease from ulcerative colitis (area under ROC curve of 0.82), and Crohn's disease from all other diagnoses (area under ROC curve of 0.77 ).
TABLE 3

Utility of anti-Saccharomyces cerevisiae antibody testing, using a cutoff of 20 binding units, comparing Crohn's disease (CD) sera with those of ulcerative colitis (UC) and other diagnoses

\begin{tabular}{lcc}
\hline & $\begin{array}{c}\text { CD }(\mathbf{n}=\mathbf{5 1}) \\
\text { versus } \mathbf{~ U C ~}(\mathbf{n = 3 2})\end{array}$ & $\begin{array}{c}\text { CD }(\mathbf{n}=\mathbf{5 1}) \\
\text { versus other* }(\mathbf{n}=\mathbf{4 8})\end{array}$ \\
\hline Sensitivity & 51.0 & 50.9 \\
Specificity & 100 & 95.8 \\
Positive predictive value & 100 & 92.9 \\
Negative predictive value & 56.1 & 64.8 \\
Correctly classified & 69.9 & 72.7 \\
\hline
\end{tabular}

*Includes 32 UC, one $C D$, one lymphocytic colitis and 14 normal controls. One patient with indeterminate colitis was positive and left out of the analysis. Fifteen patients (eight $C D$, six UC, one indeterminate) had samples from different days run; 14 (93.3\%) gave concordant results and one (6.9\%) gave discordant results. Twenty-one patients $(13 C D$, eight UC) had samples from the same day run on different days; $100 \%$ gave concordant results

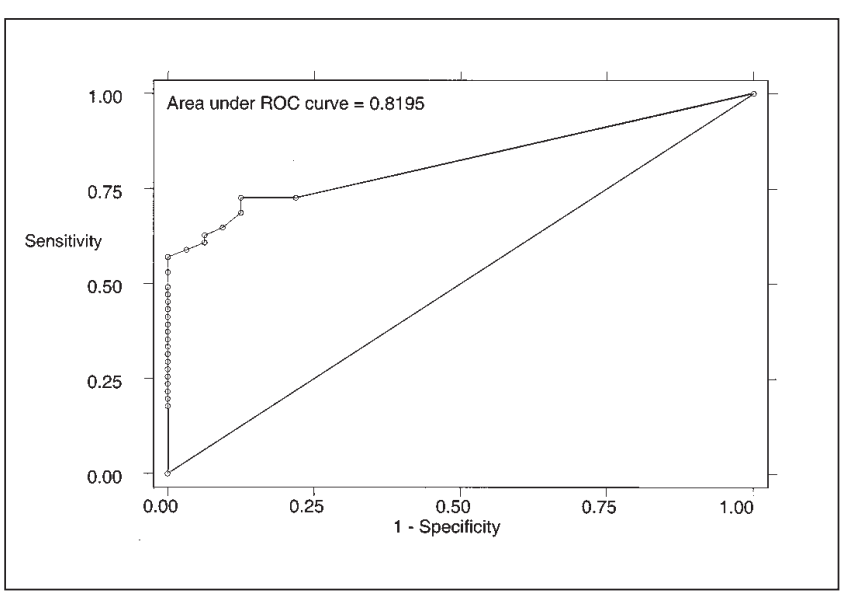

Figure 1) Receiver operating characteristic (ROC) curve for distinguishing Crohn's disease from ulcerative colitis

Table 4 compares patients with Crohn's disease who were ASCA positive $(n=27)$ with those who were ASCA negative $(n=24)$. For the purposes of this comparison, a positive ASCA test was considered to be a result of at least 15 binding units. By using 15 binding units as the cutoff for positivity, sensitivity is minimally sacrificed while the specificity for Crohn's disease is increased compared with that for all other diagnoses.

Patients with Crohn's disease who were ASCA positive were significantly younger when their disease was diagnosed $(21.3 \pm 1.1$ years $)$ than those who were ASCA negative (32.7 \pm 2.8 years, $\mathrm{P}=0.0006)$. ASCA-positive patients were more likely to have proximal disease (involving the stomach, duodenum and/or jejunum) $(\mathrm{P}=0.03)$ and were less likely to have inflammatory disease than fibrostenotic or penetrating disease $(\mathrm{P}=0.01)$ than were ASCA-negative patients. When comparing the prevalence rates of having fibrostenotic versus other types or penetrating versus other 


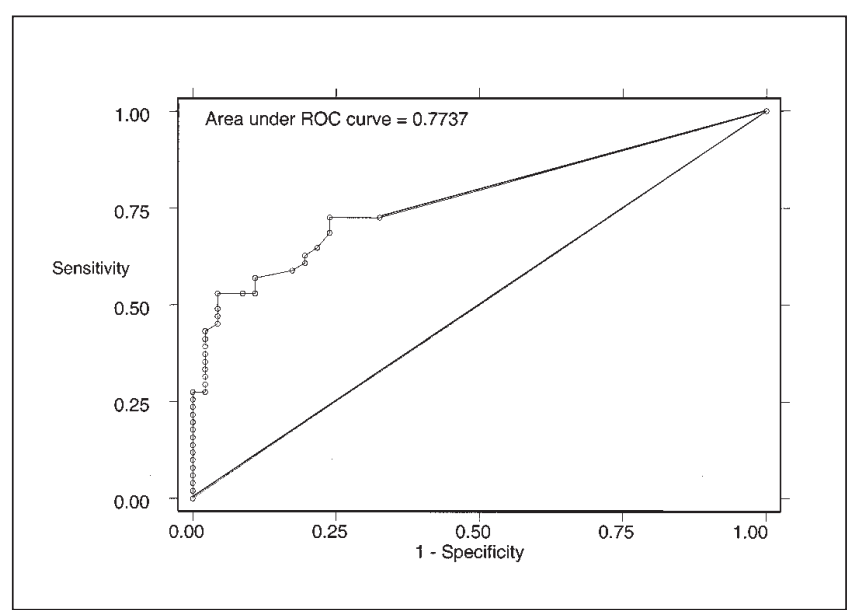

Figure 2) Receiver operating characteristic (ROC) curve for distinguishing Crohn's disease from all other diagnoses

types of disease, the differences were not statistically significant. ASCA-negative patients were more likely to have isolated colonic disease than were ASCA-positive patients $(\mathrm{P}=0.01)$.

\section{DISCUSSION}

It is unclear what role ASCA has in Crohn's disease. It may be linked to increased intestinal permeability in patients with Crohn's disease, which in turn allows increased exposure of the intestinal immune system to ingested yeasts (and other antigens). In the absence of an understanding of its pathogenetic role (if one even exists), ASCA may still have great utility as a marker for Crohn's disease. It is of interest that $10 \%$ of celiac patients' sera tested were also positive by ASCA. This may further support the notion that small bowel pathology is critical to allowing ASCA production. However, celiac disease is associated with microscopic colitis, and we do not know whether the patients who were positive for celiac disease also had colonic pathology. This will be studied further as we prospectively evaluate the use of ASCA in investigating gastrointestinal disorders in adults. Nonetheless, our data show that a significantly higher proportion of ASCA-positive patients had proximal disease in the stomach, duodenum or jejenum, and a higher proportion of ASCA-negative patients had disease in their colon only, and not also in their ileum. This suggests that either small bowel pathology allows for antibody generation to $S$ cerevisiae or the host response to this microbe leads to proximal small bowel disease.

Researchers at the University of Montreal, Montreal, Quebec studied their pediatric population and found that ASCA and pANCA testing can help establish which children with gastrointestinal complaints should undergo further invasive testing (13). Although it is important to find means of limiting invasive investigations and, therefore, limiting potential harm with improved cost saving, it is more likely for adults than for children that investigations will proceed regardless of a serological test result. Although
TABLE 4

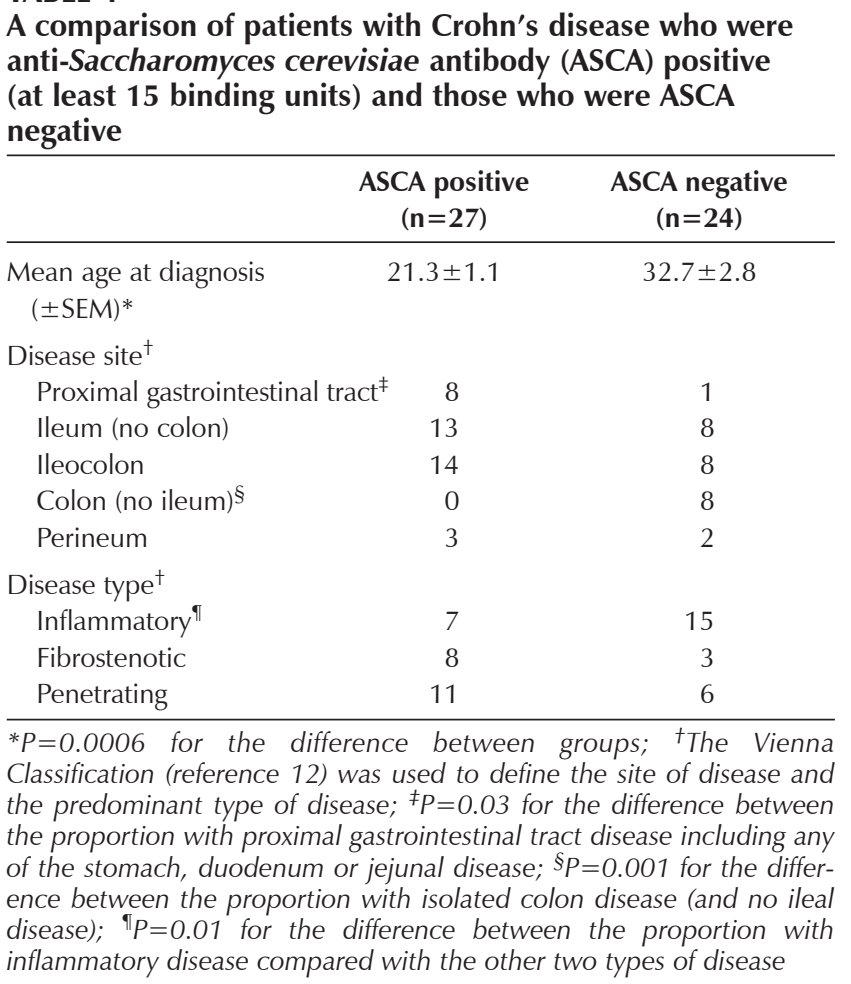

our test has proved to have a low sensitivity, its high degree of specificity, particularly when differentiating between Crohn's disease and ulcerative colitis, makes it a worthwhile addition for clinicians. ASCA may have an important role for the clinical problem of solving indeterminate colitis. The utility of this assay for indeterminate colitis would have to be proven by subjecting patients with this diagnosis to ASCA testing and prospectively following over time how well ASCA could help discriminate between patients ultimately proving to have Crohn's disease and those proving to have ulcerative colitis. Our assay is a welcome addition to help us begin to understand the utility of ASCA in indeterminate colitis. At the sensitivity rates that we used, our assay may have a lesser utility in identifying family members who are seropositive and, therefore, may have preclinical disease (14-16). Currently, this application of the test is mostly for research purposes. One other consideration for the use of serological testing is that of identifying disease phenotype (17). Our data certainly support that our ASCA assay distinguishes a group of patients with Crohn's disease who are likely to present with their disease at a significantly younger age, with proximal gastrointestinal disease and with penetrating disease. ASCA-negative patients are more likely to have isolated colonic disease and also inflammatory disease as opposed to fibrostenotic disease or penetrating disease.

When a sample is sent to Prometheus Laboratories for ASCA testing, there is a charge of US $\$ 140$ (approximately CDN\$210) per negative sample. Not only is ASCA run, but a collection of inflammatory bowel disease-associated antibodies, including ASCA and pANCA, are also run. If 
the test is positive, Prometheus Laboratories will pursue a more indepth antibody screen for US $\$ 445$ (approximately $\mathrm{CDN} \$ 670)$. It is hard to imagine that, at these rates, this test will prove to be cost effective in Canadian centres. Our referred-in charge for the ASCA assay is $\$ 38.15$. These charges reflect direct and indirect costs. If a follow-up ANCA is required, an additional charge of $\$ 35.00$ is invoiced. It is not the anticipated approach of this centre to automatically run ANCA assays on patients who have ASCA assays ordered, whether or not they are positive. The utility of such an approach may be better appreciated after completion of an ongoing prospective study to evalu-

\section{REFERENCES}

1. Saxon A, Shanahan F, Landers C, et al. A distinct subset of antineutrophil cytoplasmic antibodies is associated with inflammatory bowel disease. J Allergy Clin Immunol 1990;86:202-10.

2. Duerr RH, Targan SR, Landers CJ, et al. Anti-neutrophil cytoplasmic antibodies in ulcerative colitis: comparison with other colitides/ diarrheal illnesses. Gastroenterology 1992;100:1590-6.

3. Cambridge G, Rampton DS, Stevens TRJ, et al. Antineutrophil cytoplasmic antibodies in inflammatory bowel disease: prevalence and diagnostic role. Gut 1992;33:668-74.

4. Rutgeerts P, Vermeire S. Clinical value for the detection of antibodies in the serum for diagnosis of inflammatory bowel disease. Gastroenterology 1998;115:1006-22.

5. Vidrich A, Lee J, James E, et al. Segregation of pANCA antigenic recognition by DNAse treatment of neutrophils: ulcerative colitis, type I autoimmune hepatitis and primary sclerosing cholangitis. J Clin Immunol 1995;15:293-9.

6. Price AB. Overlap in the spectrum of non-specific inflammatory bowel disease - "colitis indeterminate". J Clin Pathol 1978;31:567-77.

7. Vasiliauskas EA, Plevy SE, Landers CJ, et al. Perinuclear antineutrophil cytoplasmic antibodies in patients with Crohn's disease define a clinical subgroup. Gastroenterology 1996;110:1810-9.

8. Reummele FM, Targan SR, Levy G, Dubinsky M, Braun J, Seidman EG. Diagnostic accuracy of serological assays in pediatric inflammatory bowel disease. Gastroenterology 1998;115:822-9.

9. Main J, McKenzie H, Yeaman GR, et al. Antibody to Saccharomyces cerevisiae (baker's yeast) in Crohn's disease. BMJ 1988;297:1105-6.

10. Sendid B, Colombel JF, Jacquinot PM, et al. Specific antibody ate these tests in a variety of gastrointestinal patients. However, regardless of cost, these tests may have an important role in differentiating cases of indeterminate colitis. Most centres in Canada are now performing pANCA testing. We have proved that it is relatively simple to establish a specific ASCA test as well.

ACKNOWLEDGEMENTS: Dr Charles N Bernstein is supported in part by a research scientist award jointly funded by the Crohn's and Colitis Foundation of Canada and the Canadian Institutes of Health Research. response to oligomannosidic epitopes in Crohn's disease. Clin Diagn Lab Immunol 1996;3:219-26.

11. Quinton JF, Sendid B, Remaux D, et al. Anti-Saccharomyces cerevisiae mannan antibodies combined with anti-neutrophil cytoplasmic antibodies in inflammatory bowel disease: prevalence and diagnostic role. Gut 1998;42:788-91.

12. Gasche CG, Scholmerich J, Brynskov J, et al. A simple classification of Crohn's disease: Report of the Working Party for the World Congress of Gastroenterology, Vienna 1998. Inflamm Bowel Dis 2000;6:8-15.

13. Dubinsky MC, Ofman JJ, Urman M, Targan SR, Seidman EG. Clinical utility of serodiagnostic testing in suspected pediatric inflammatory bowel disease. Am J Gastroenterol 2001;96:758-65.

14. Vermeire S, Peeters M, Vlietinck R, et al. Anti-Saccharomyces cerevisiae antibodies (ASCA), phenotypes of IBD, and intestinal permeability: A study in IBD families. Inflamm Bowel Dis 2001;7:8-15.

15. Sendid B, Quinton J-F, Charrier G, et al. Anti-Saccharomyces cerevisiae mannan antibodies in familial Crohn's disease. Am J Gastroenterol 1998;93:1306-10.

16. Sutton CL, Yang H, Li Z, et al. Familial expression of antiSaccharomyces cerevisiae mannan antibodies in affected and unaffected relatives of patients with Crohn's disease. Gut 2000;45:58-63.

17. Quinton JF, Sendid B, Remaux D, et al. Anti-Saccahormyces cerevisiae mannan antibodies combined with anti-neutrophil cytoplasmic antibodies in inflammatory bowel disease: prevalence and diagnostic role. Gut 1998;42:788-91. 


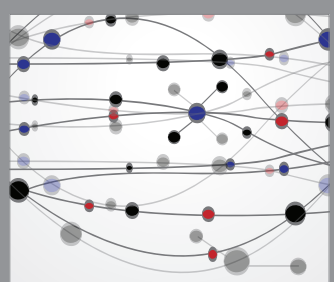

The Scientific World Journal
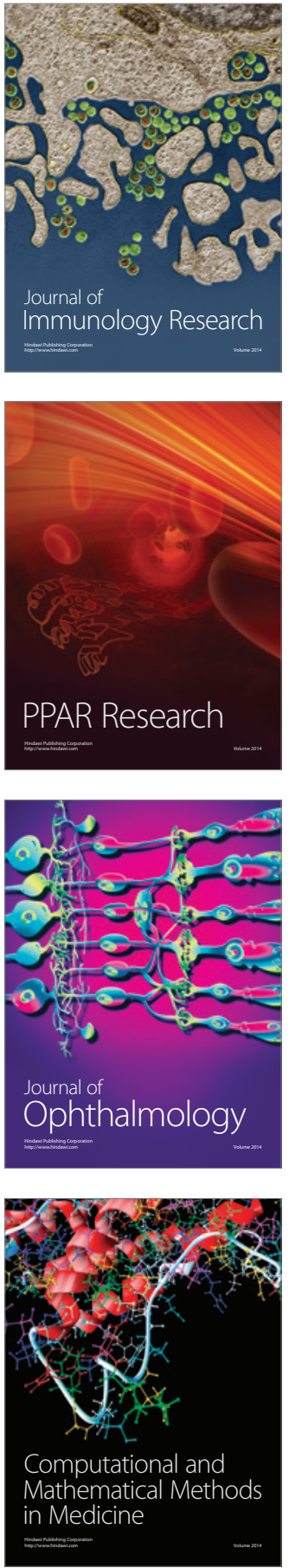

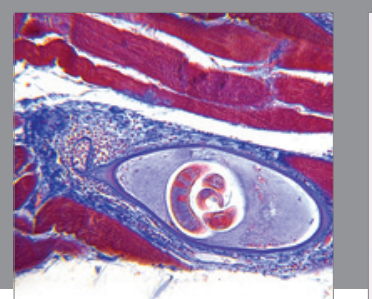

Gastroenterology Research and Practice

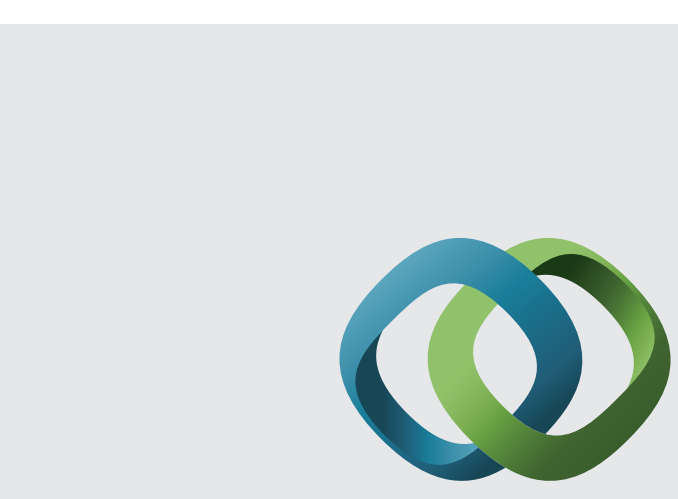

\section{Hindawi}

Submit your manuscripts at

http://www.hindawi.com
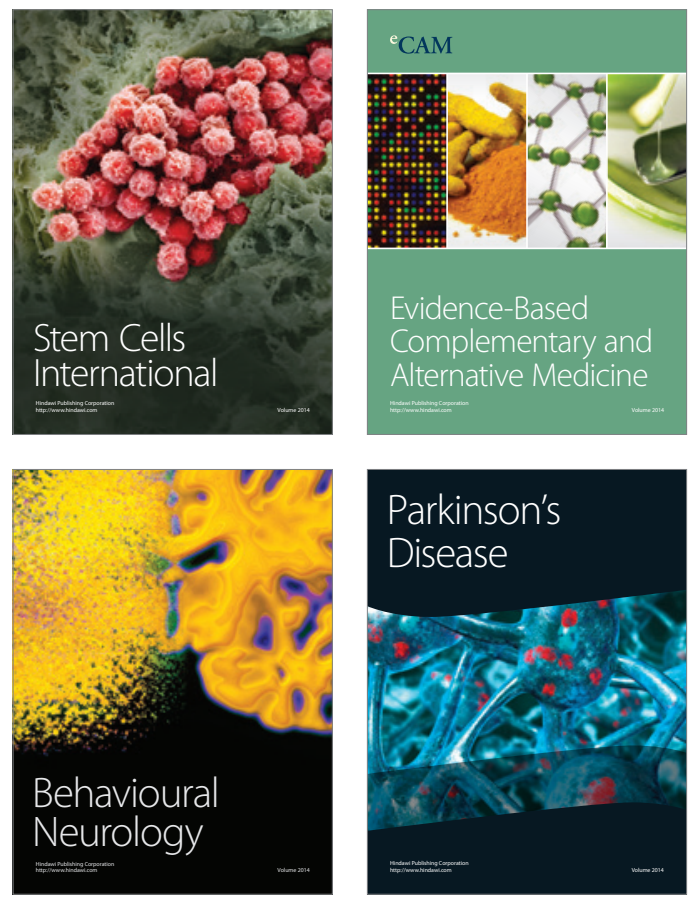
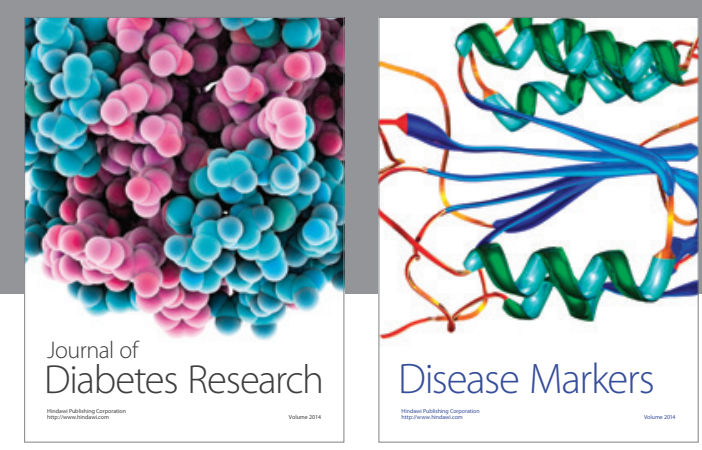

Disease Markers
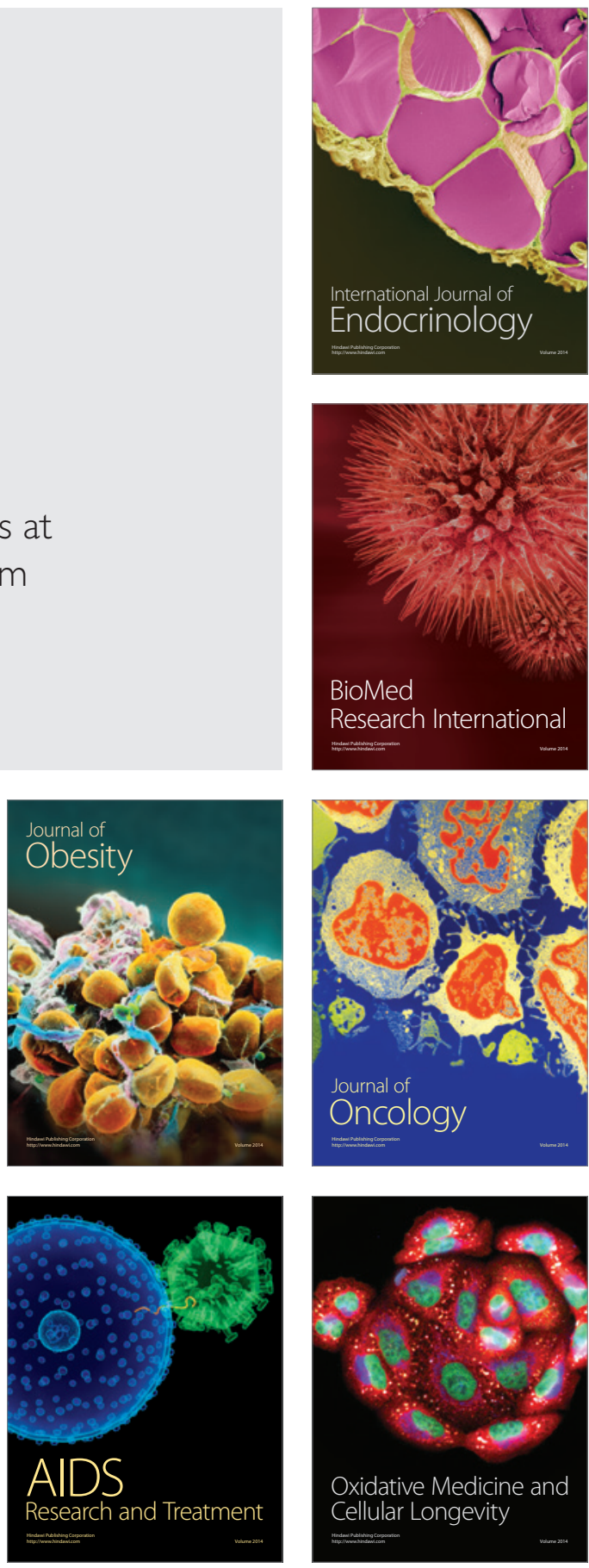